\title{
ASPECTOS ANÔMALOS DA RECLAMAÇÃO PERANTE O CÓDIGO DE PROCESSO CIVIL
}

Paulo Ricardo Cavalcante de Siqueira

Especialista em Direito Público pela Universidade Vale do Acaraú. Advogado.

paulinhosiqueira@terra.com.br

Sumário: Introdução. 1) Exposição preliminar e caracteres da reclamação. 2) A reclamação ante às legislações ordinárias e constitucional. Considerações finais.

Resumo: A reclamação é um instituto que tende a funcionar como remédio inespecífico e supletivo. Apesar da existência de divergências pontuais, a reclamação é pacífica quanto à sua relevância para a efetividade do processo. Ela tem previsão legal nos Regimentos Internos dos Tribunais brasileiros. A reclamação assume características visíveis de anomalia, frente à sistemática processual civil brasileira. A carência, e por vezes inexatidão, de regulamentação faz com que seu entendimento se torne comprometido. Reclamação é remédio judiciário de caráter correcional que objetiva impugnar atos ou omissões de juízes de primeiro grau de jurisdição que por natureza seriam irrecorríveis.

Palavras-chave: Reclamação. Regimento Interno. Recurso.

\section{INTRODUÇÃO}

Há uma tendência, sob aplausos de tribunais brasileiros, para erigir a reclamação à categoria de recurso especial, distinto dos demais, funcionando como remédio inespecífico e supletivo.

A inclinação que comporta ponderáveis exceções assume características visíveis de anomalia, frente à sistemática processual civil brasileira, mais objetivamente se observado o sistema recursal.

Talvez o apego aos princípios tradicionais consolidados no elastério sempre dominante da variedade de formas de como recorrer na legislação pretérita, tenha determinado o emprego da reclamação além de suas fronteiras naturais, atingindo limites vedados pela Carta Magna do país.

Diante da incerteza que a reclamação atravessa em nosso direito para cristalizar-se, nada está assentado, teoricamente, sobre a sua verdadeira e definitiva posição jurídica no campo processual. 
Motivo de constante dúvida, a reclamação é por poucos conhecida, o que por si só é ensejadora de uma explanação.

A escolha da reclamação como tema para discussão se justifica pela escassa referência que a ela dedica, de modo direto, a bibliografia jurídica, quando pela diária aplicação do remédio na lide forense, carece de uma atuação precisa e fora de vacilações.

Abortada, mais freqüentemente, sob o foco constitucional, a reclamação necessita de explicações relativas à sua utilização no âmbito dos Tribunais de Justiça.

É preciso que se trace com precisão o roteiro por onde a reclamação haverá de caminhar decisivamente.

A razão para este trabalho é que as questões relativas à reclamação pouco têm sido objeto de discussões e estudos, e apesar disso apresenta profundas divergências. $\mathrm{O}$ correto e completo entendimento do tema possibilitará a visualização dos aspectos que envolvem a natureza e a forma da reclamação perante o sistema jurídico.

Tem-se, então, como objetivo geral, analisar o instituto da reclamação, diante do Código de Processo Civil com base nos fundamentos doutrinários, jurisprudenciais e legislativos.

Os objetivos específicos são: abordar o posicionamento do direito positivo brasileiro frente ao instituto da reclamação; verificar como pode se dar a reclamação no âmbito dos Tribunais de Justiça; analisar a natureza da reclamação.

Em traços gerais, deixando à margem as decisões que revestem cunho extraprocessual civil, para observar as que manifestam finalidades que se equiparam, na prática, a verdadeiros recursos, como suplemento dos que existem hoje, cabe o presente estudo capaz de, purificando as linhas doutrinárias, explicar os aspectos de anomalia que a reclamação apresenta.

Com a explicação, quer parecer introduzido o tema, particularmente ligado à processualística e integrado no dia-a-dia dos operadores do Direito.

\section{EXPOSIÇÃO PRELIMINAR E CARACTERES DA RECLAMAÇÃO}

A reclamação, prevista nos Regimentos Internos dos Tribunais de Justiça de alguns Estados, assume características de anomalia perante o Código de Processo Civil, funcionando como remédio inespecífico e supletivo, com resultados práticos similares aos dos recursos.

Diz José da Silva Pacheco (1989, p. 12), depois de catalogar os recursos vigentes no CPC, que: além desses recursos específicos, torna-se cada dia mais em uso a reclamação, cogitada pela generalidade das leis de organização judiciária.

Realidades forenses, portanto, atuando na esfera do direito codificado, sob pretexto de que os juízes agem ao influxo de atribuição construtiva, impulsionaram 
o Judiciário a um papel legislativo inadequado à sua condição estrutural, diante dos exageros que repontam, por vezes, da singular criação.

$\mathrm{O}$ instituto, que teima em fixar raízes transcendentes aos definidos intuitos do legislador federal ordinário é, assim, nesse raio de ação extensivo, dependente de regulamentação apropriada.

\subsection{ETIMOLOGIA E ACEPÇÕES DO TERMO RECLAMAÇÃO}

O vocábulo reclamação se traduz por reclamar + ação, do latim reclamatione, ou como afirma Aurélio Buarque de Holanda Ferreira (2007, p. 487): ato ou efeito de reclamar; queixa; opor-se; fazer impugnação ou protesto (verbal ou por escrito).

Esse é o sentido comum.

$\mathrm{Na}$ linguagem jurídica não foge ao significado de inconformação.

É, ainda aí, um protesto, uma oposição, até mesmo no sentido extensivo, um meio de reivindicar direitos.

Traz Guillermo Cabanellas De Torres (2006, p. 406), em seu Diccionario Juridico Elemental o verbete: Reclamación - la oposición que de escrito o de palabra se hace contra alguna cosa no consintiéndola o considerándola injusta. La reclamación puede ejercerse en forma privada o judicialmente, y puede tener por causa un acto jurídico o una disposición legal.

O conteúdo da palavra, na terminologia especializada, assume um caráter restrito que comporta duas idéias principais.

Primeiro, pode traduzir, em princípio, um modo para defesa de um direito, inclusive para significar ação (sentido jurídico lato sensu).

Segundo, mais particularmente, quer dizer veículo de manifestação de um desagrado, que parece ao reclamante merecedor de correção por parte da autoridade judiciária de grau superior (sentido jurídico stricto sensu).

No entendimento jurídico amplo está por demais difundido o termo reclamação como sinônimo de ação no Processo do Trabalho sob a forma de dissídio individual, conforme os artigos 837 e seguintes da Consolidação das Leis do Trabalho.

Ao lado dessa compreensão figura o sentido jurídico estrito em que expressa remédio judiciário de caráter correcional e, às vezes, por hipertrofia, o significado de recurso, embora impróprio, tanto no setor processual civil, como no ramo do Direito Penal.

\subsection{INCLINAÇÕES JURISPRUDENCIAIS}

A jurisprudência não pode se sobrepor à lei. Existe um conjunto de regras por onde deve caminhar a jurisprudência, podendo transitar dentro dos limites sem porém ultrapassá-los, sob pena de se aventurar na inconstitucionalidade. 
A ninguém é dado, entretanto, desconhecer ou obstacular o seu sentido construtivo fazendo da norma legal instrumento vivo de realização do direito.

A Justiça não pode ser indiferente às novas formas com que o presente procura modificar o futuro. A capacidade de construção jurídica foi sempre um dos atributos das grandes jurisprudências. Elas, em muitos casos, se anteciparam no tempo, propondo para hoje os ideais de justiça somente imagináveis com uma lenta evolução doutrinária.

Porém, as construções da jurisprudência por sua atividade restrita, no tocante ao ponto que se está examinando, desempenhando um papel importantíssimo, traduzem tendências que nem mesmo conseguiram um sentido uniforme.

Muito natural é essa disparidade jurisprudencial, porque, se os julgadores não se abrigam debaixo de um só pensamento quando é unitária a lei a aplicar, quando estão diversificados os princípios que informam o seu modo de agir ocorrerá divergência ainda mais asseverada.

Simultaneamente à vocação correcional, sobressai na multiplicidade dos acórdãos outra propensão, hipertrófica, de índole inovadora, procurando fazer da reclamação um recurso para quando não haja uma modalidade específica no quadro regular.

Debaixo desse aspecto, apenas em uma breve busca na jurisprudência brasileira, colhem-se alguns Julgados esclarecedores.

Segue a ementa do agravo regimental n. 22/03 do Juizado Especial Cível da Comarca de Balneário Camboriú:

AGRAVO REGIMENTAL CONTRA ACÓRDÃO QUE RECONHECEU A DESERÇÃO RECURSAL - DECISUM PROFERIDO POR COLEGIADO E NÃO MEDIANTE DESPACHO DO PRESIDENTE OU DO RELATOR - INTELIGÊNCIA DO ART. 27, PARÁGRAFO ÚNICO, DO REGIMENTO INTERNO - NÃO CONHECIMENTO. RECLAMAÇÃO, NO MESMO RECURSO, QUANTO AO FATO DE NÃO HAVER CONSTADO DA PUBLICAÇÃO DO EDITAL DE JULGAMENTO, A APELAÇÃO CÍVEL JULGADA DESERTA - ERRO IN PROCEDENTO DA SECRETARIA, RECONHECIDO - INFRAÇÃO AO DISPOSTO NO ART. 51 DO REGIMENTO INTERNO DAS TURMAS DE RECURSO DO ESTADO DE SANTA CATARINA - JULGAMENTO ANULADO - INCONFORMIDADES EM RELAÇÃO À DESERÇÃO, JULGADAS PREJUDICADAS. (grifo nosso)

E isso para não se falar em outras variações que conduzem a fim idêntico, como se pode observar na Reclamação n. 2007.700431-2, de Balneário Camboriú - DJE n. 229, de 20/06/2007:

RECLAMAÇÃO - JUIZADO ESPECIAL CÍVEL - CONTINÊNCIA NÃO EVIDENCIADA ENTRE AS DEMANDAS - POSSIBILIDADE DE 
DECISÕES CONTRADITÓRIAS INEXISTENTE - EXEGESE DO ARTIGO 104 DO CÓDIGO DE PROCESSO CIVIL - RECURSO CONHECIDO E PROVIDO - DECISÃO CASSADA.

Certas decisões dão restrição à admissibilidade da forma reclamatória, exigindo, além da ausência do recurso específico, que haja decisão que contenha erro ou abuso, que importe inversão da ordem legal. Como na Reclamação $n$. 2007.701870-3, de Itajaí - DJE n. 271, de 17/08/2007:

Os requisitos necessários para acolhimento do pedido de Reclamação encontram-se normatizados no artigo 126 do Regimento Interno das Turmas de Recursos: "Caberá reclamação de decisão que contenha erro ou abuso, que importe da inversão da ordem legal do processo, quando para o caso não haja recurso específico".

Não falta na variação de opiniões o combate aberto à reclamação, em uma tendência incontida de repulsa formal ao remédio, por parte de alguns juízes.

É verdade que sobre o assunto não é uniforme a jurisprudência dos Tribunais do País.

Se muitos consideram inadmissível a reclamação como recurso, vários outros a consideram meio hábil, na falta de recurso específico, para evitar ofensa ao direito da parte ou à ordem processual.

Em tão contraditório modo de entender, a palavra dos Tribunais constitui, no assunto, como em muitos outros, uma palpável interrogação.

A compreensão díspar não acarretaria desfecho ao sentido de dúvida ainda existente quanto à reclamação, apesar de já haver sido chamada de recurso instituído pela jurisprudência.

\subsection{INCLINAÇÕES DOUTRINÁRIAS}

Diante da incerteza que a reclamação atravessa para cristalizar-se, nada está assentado teoricamente sobre a sua verdadeira e definitiva posição jurídica no campo processual.

Trata-se de uma medida que enseja, na sua conceituação, problemas oriundos da falta de precisão do roteiro por que haverá de caminhar decisivamente.

Para Cândido Rangel Dinamarco (2004, p. 196) a reclamação é tida por sua natureza jurídica como remédio processual sem natureza recursal.

Francesco Carnelutti (apud DINAMARCO, 2003, p. 09) esclarece a respeito dos remédios processuais:

A reclamação enquadra-se comodamente na categoria dos remédios processuais, que é muito ampla e abriga em si todas as medidas as quais, de algum modo, se afasta a 
eficácia de um ato judicial viciado, se retifica o ato ou se produz sua adequação aos requisitos da conveniência ou da justiça (Carnelutti). (grifos do autor).

Ainda, segundo Cândido Rangel Dinamarco (2003, p. 09) o vocábulo reclamação: Ora é empregado como sinônimo de correição parcial, designando remédio processual destinado a impugnar atos ou omissões do juiz do primeiro grau de jurisdição, insuscetíveis do recurso de agravo; ora designa o meio mediante o qual se leva ao STF [....].

A natureza recursal da reclamação, não obstante defendida por alguns, não encontra respaldo no ordenamento jurídico processual atual.

Segundo Moacyr Amaral dos Santos (Reclamação n. 831 - DF RTJ 56/53950) a reclamação tem natureza de recurso, e estabeleceu como pressupostos:

a) a existência de uma relação processual em curso; b) um ato que se ponha contra a competência do Supremo Tribunal ou que contrarie decisão deste, proferida nessa relação processual ou em relação processual que daquela seja dependente.

Apesar de defendida, esta corrente não pode vingar. Certo é que a reclamação se assemelha na prática aos recursos, porém conferir-lhe natureza recursal é ultrapassar o limite do aceitável. Isto porque, os recursos são elencados expressamente em lei, não havendo qualquer dispositivo legal que lhe atribua referida natureza. Tê-lo como tal implicaria em afronta ao princípio da taxatividade.

Arrazoa Rui Portanova (2005, p.269):

Em virtude do princípio da taxatividade, só podem servir como recurso os instrumentos especificamente previstos em lei federal, quer seja via Código de Processo Civil, quer seja por outra lei de mesma hierarquia. A enumeração legal não é exemplificativa, mas taxativa. A interpretação neste caso é restritiva, e não ampliativa.

Nelson Nery Júnior (2004, p. 85) faz alusão à reclamação em duas passagens de sua obra. Na primeira delas equipara a expressão à correição parcial, para concluir tratar-se de medida administrativa. Em um segundo momento, aborda a reclamação prevista na CF, de competência do Superior Tribunal de Justiça e do Supremo Tribunal Federal. Nestas hipóteses o autor não alude à natureza administrativa da medida, mas afasta a sua natureza recursal.

Digno de nota é o que observa Ada Pellegrini Grinover (2002, p.79-80), no sentido de que a reclamação constitui simples exercício do direito de petição, não se caracterizando como recurso, ação ou incidente processual:

A meu ver, a providência em questão constitui uma garantia especial que pode ser subsumida na cláusula constitucional que assegura "o direito de petição aos Poderes Públicos em defesa de direito ou contra a ilegalidade ou abuso de poder" (CF, art. $5^{\circ}, \mathrm{XXXIV,} \mathrm{a).} \mathrm{(grifos} \mathrm{do} \mathrm{autor)}$ 
Este posicionamento é o acatado pelo STF, como visto no julgamento da ADIn 2.212-1-CE, onde o Supremo analisava em sede de controle concentrado a constitucionalidade de artigo da Constituição do Estado do Ceará, que previa o cabimento da reclamação para o Tribunal de Justiça do Estado.

AÇÃO DIRETA DE INCONSTITUCIONALIDADE. ARTIGO 108, INCISO VII, ALÍNEA J DA CONSTITUIÇÃO DO ESTADO DO CEARÁ E ART. 21, INCISO VI, LETRA J DO REGIMENTO DO TRIBUNAL DE JUSTIÇA LOCAL. PREVISÃO NO ÂMBITO ESTADUAL, DO INSTITUTO DA RECLAMAÇÃO. INSTITUTO DE NATUREZA PROCESSUAL CONSTITUCIONAL, SITUADO NO ÂMBITO DO DIREITO DE PETIÇÃO PREVISTO NO ARTIGO 5 ${ }^{\circ}$, INCISO XXXIV, ALÍNEAADA CONSTITUIÇÃO FEDERAL. INEXISTÊNCIA DE OFENSAAO ART. 22, INCISO I DA CARTA. 1. A natureza jurídica da reclamação não é a de um recurso, de uma, ação e nem de um incidente processual. Situa-se ela no âmbito do direito constitucional de petição previsto no artigo $5^{\circ}$, inciso XXXIV da Constituição Federal. Em conseqüência, a sua adoção pelo Estado-membro, pela via legislativa local, não implica em inversão da competência privativa da União para legislar sobre direito processual (art. 22, I da CF).

2. A reclamação constitui instrumento que, aplicado no âmbito dos Estadosmembros, tem como objetivo evitar, no caso de ofensa à autoridade de um julgado, o caminho tortuoso e demorado dos recursos previstos na legislação processual, inegavelmente inconvenientes quando já tem a parte uma decisão definitiva. Visa, também, à preservação da competência dos Tribunais de Justiça estaduais, diante de eventual usurpação por parte de Juízo ou outro Tribunal local. 3. A adoção desse instrumento pelos Estados-membros, além de estar em sintonia com o princípio da simetria, está em consonância com o princípio da efetividade das decisões judiciais.

4. Ação direta de inconstitucionalidade improcedente.

(STF - ADIn 2.212/CE. Rel. Min. Ellen Gracie, DJU de 14.11.2003 - p. 00011).

A referida norma fora impugnada dada sua natureza processual sendo, por isso, vedada sua previsão em lei estadual, face ao disposto no art. 22, I da CF. No entanto o STF ao afastar a natureza de ação e classificar a reclamação como simples exercício do direito de petição, julgou constitucional a norma, afastando a ofensa ao citado artigo.

Não é, contudo, a opinião de José da Silva Pacheco (1989, p. 30), que confere à reclamação natureza de ação, afirmando tratar-se de:

Ação fundada no direito de que a resolução seja pronunciada por autoridade judicial competente; de que a decisão já prestada por quem tinha competência para fazê-lo tenha plena eficácia, sem óbices indevidos ou se elidam os estorvos que se antepõem, se põem ou se pospõem à plena eficácia da decisão ou a competência para decidir. 
Para Leonardo L. Moreato (2005, p. 174), este instituto tem a ver, antes de tudo, com a efetividade do processo, porque não se pode falar em processo efetivo sem que se garanta a autoridade das decisões judiciais; e, finalmente, com a sobrevivência e a efetividade do nosso sistema, com o Estado Democrático de Direito.

É certamente o mais arrazoado, tratando-se, em última análise, de mais um meio para se poder alcançar a tão almejada justiça.

\subsection{OBJETO E REQUISITOS}

A reclamação tem um objetivo definido, que não é para desprezar, dada a utilidade de seu emprego.

$\mathrm{Na}$ verificação desse fim é de mister fixar os conceitos oriundos dos princípios gerais consagrados pela jurisprudência e os assentos concebidos pela legislação dos Estados, e as disposições dos Regimentos de Tribunais, de par com a incipiente doutrina que se vem formando à sua margem.

Não resta dúvida de que ela é um remédio de disciplina judiciária com a finalidade de corrigir situações tumultuadas criadas no processo, quando para o caso inexiste recurso específico.

No dizer de José da Silva Pacheco (1989, p. 865): é a invocação do Tribunal ou do Conselho de Justiça do Tribunal para o acertamento do processo, quando o juiz estiver, na direção do feito, praticando atos que importem na inversão tumultuária da ordem processual.

Esse é o seu real propósito, não importando que, por hipertrofia, a reclamação seja entendida mais elasticamente.

Se assim o quiser, ou seja, ampliar o seu campo de atuação, deve-se vislumbrá-la no seu significado à equiparação integral aos recursos, almejando a proteção de direitos violados, pura e simplesmente quando os recursos normais se apresentassem insuficientes.

No verdadeiro intento, com o caráter disciplinar, os requisitos que se mostram podem ser assim expressados: a) que do despacho reclamado não caiba recurso ordinário; b) que encerre o mesmo despacho, erro ou abuso, que importe a inversão tumultuária da ordem legal do processo.

Logo, os elementos da medida reclamatória estão consubstanciados na inexistência de recurso específico para o caso e na necessidade de chamar o processo à ordem, por erro ou abuso de poder que tragam a sua perturbação.

Impõem-se tais requisitos de parelha com os outros que dizem respeito à sua interposição e processo.

Admitida com a função de recurso, de certo que desnecessário seria o implemento de condições além da simples falta de uma modalidade prevista em lei, para recorrer, guardados os naturais, pouco importando o tumulto processual porventura existente. 


\subsection{INTERPOSIÇÃO, PRAZO E OUTRAS PECULIARIDADES DE PROCESSAMENTO}

Com funcionalidade de recurso a reclamação deveria ser interposta por quem sofresse o gravame.

Competiria a interposição tanto a parte propriamente dita como ao Ministério Público, ao figurar como interessado na lide e, por extensão, também ao terceiro interessado.

Na reclamação correcional, pela letra das disposições vigorantes, a faculdade de interpor cabe aos interessados.

As Leis de Organização Judiciária e os Regimentos dos Tribunais ora aludem às partes, ora aos interessados, e alguns, mais categoricamente, aos interessados ou ao Ministério Público.

No Distrito Federal, por exemplo, a reclamação compete ao interessado ou ao Procurador Geral, enquanto é conferida em São Paulo aos interessados ou ao Ministério Público e, em Alagoas ou no Ceará, às partes.

Há regimentos, como o do Pará, que silenciam a respeito.

Em matéria de prazo existe certa uniformidade de entendimento nos preceitos estabelecidos.

Assim é que as regras expressas sempre se atêm a um período de cinco dias a contar de quando o interessado conheceu do ato a reclamar.

Tem prevalecido no direito positivo brasileiro, razoavelmente, o critério de prazo mais curto nas situações de menor repercussão, reservado um maior tempo para que sejam formulados recursos mais importantes.

Daí o prazo da apelação ser maior em cinco dias do que o tempo de propositura de um agravo. O legislador vislumbra, ao que tudo indica, o alto significado da apelação e as naturais dificuldades para ser intentada, envolvendo quase sempre, matéria mais complexa e elástica.

Nesse tocante o assunto sugere uma apreciação que demonstra o as-pecto incoerente, revelador da inconsistência da reclamação tal como está amparada regionalmente.

A conseqüência inicial da formulação de recurso é impedir a produção normal dos efeitos da sentença, isto é, que as interlocutórias não assumam caráter preclusivo e nem as definitivas, o de coisa julgada.

Fosse a reclamação havida por recurso, fatalmente ensejaria um desses resultados.

Porém, se existe um prazo predeterminado para que seja interposta, como não é amparada por lei federal unificada, a falta de propositura do remédio, diante do cunho extralegal em apreço, deixa de determinar preclusão e, muito menos, pode fazer coisa julgada, diferentemente do que ocorre com a falta de formulação de agravo no caso de cerceamento de defesa, por exemplo.

Quanto ao rito empregado, a reclamação, excepcionalmente, permite a avocação dos autos da questão principal, sendo o comum o seu conhecimento através de peças extraídas daquele processo. 
O modo de proceder traz vantagens indiscutíveis, mormente se entendido, conforme Egas Moniz de Aragão (1969, p.107-108) que a reclamação não é um recurso e, portanto, sem força para obstacular o seguimento do processo, paralisando-o, tal como se comportasse efeito suspensivo:

Não parece admissível dizer que a reclamação seja, em verdade, um recurso. [....] A reclamação não tem por finalidade remover o gravame que incidiu sobre a parte através de despacho judicial errôneo ou prejudicial, nem o seu cabimento está sujeito a prazo ou à existência ou inexistência de recurso.

Ainda hipertrofiada, para servir de recurso, a formação do instrumento mostra vantagens. Realmente, por esse intermédio é levado ao julgador ad quem o material de que carece no exame a proceder e, sem prejudicar a marcha processual, ao mesmo tempo que permite pronta solução às irregularidades reclamadas, atende aos princípios da celeridade e economia preconizados na melhor doutrina.

A reclamação precisa formar-se indispensavelmente com o traslado das peças que evidenciem o ato atacado, a época em que o reclamante dele conheceu a procuração e elementos outros que instruam o julgador a respeito das realidades do tumulto no processo.

É de se observar ainda, se há ou não necessidade de um pedido de reconsideração a ser feito pelo reclamante ao juiz do ato atacado, objeto da reclamação.

Prefere-se, por ser de melhor política, a fórmula do CPC ao permitir ao juiz a reforma ou a manutenção do decisório agravado.

Bem se sabe, é de bom senso, pelo menos, se dar sempre ao julgador a possibilidade de emendar um erro, de corrigir a situação tumultuária do processo, ganhando-se tempo precioso com o possível reconhecimento da irregularidade.

Nesse apanhado do que é peculiar à reclamação tem seu destaque o ponto relacionado com o preparo dos autos. Como ocorre aos recursos, a reclamação será considerada deserta se não for preparada no tempo devido.

\section{A RECLAMAÇÃo ANTE AS LEGISLAÇÕES ORDINÁRIAS E CONSTITUCIONAL}

A legislação vigente tem sido omissa quanto à reclamação como recurso autônomo e normal. Desta feita busca-se observar como a reclamação se apresenta frente à legislação no Brasil.

Rebuscando as leis da fase colonial, do período de transição do sistema legislativo lusitano para o brasileiro e mesmo do ciclo da legislação própria, não se encontra um recurso de reclamação com essa designação específica.

Diferente, é bem verdade, o sentido processual moderno em que a expressão vem sendo utilizada na sua acepção jurídica estrita. 
Em retrospecto, a fim de se apreciar o conteúdo das Ordenações do Reino nota-se pela leitura a seguir do parágrafo $5^{\circ}$ da Compilação Filipina, datada de 1603, seus caracteres de outrora, nos seguintes termos:

E quando o arbitramento for feito pelos arbitradores approvados pelas partes, e ajuramentados, se alguma dellas se sentir aggravada, e pedir que seja reduzido ao arbítrio e bom juízo dos juizes, como dito he, podêl-o-há fazer do dia, que o arbitramento for feito, ate hum anno cumprido, queixando-se a elles do arbitramento injustamente feito, ou reclamando perante outro qualquer Julgador, stando em outra parte, e tirando disso instrumento público. E não se queixando, nem reclamando no dito anno, dahi em diante o não poderá mais contradizer, mas ficará para sempre firme, como se já segundariamente fosse aprovado pelos juízes.

A alusão invocada a título de curiosidade pelo uso já então feito da providência não guarda analogia com os aspectos principais da reclamatória de hoje, mas deixa entrever primórdios da atual reclamação.

\subsection{No Código de Processo Civil}

Através do significativo trabalho que vem aprimorar o nosso Direito Processual Civil, adaptando-o aos reclamos de processualística mais adiantada, sem abandonar, no entanto, princípios tradicionais das legislações anteriores, a construção de 73 padronizou os recursos, de modo a evitar tumultos, prolongações e confusão no curso do processo, fixando-os, nos termos do art. 496, em apelação, agravo, embargos infringentes, embargos de declaração, recurso ordinário, recurso especial, recurso extraordinário, embargos de divergência em recurso especial e em recurso extraordinário.

Fazendo essa rápida enumeração, nota-se a exclusão de um recurso reclamatório no direito positivo em vigor, sem a necessidade de se analisar o conceito dessas importantes formas, alheias ao nosso estudo, queremos dizer que elas pouco se aproximam estruturalmente da aludida construção jurisprudencial que aparece, constantemente, nos julgados.

Não se distanciaria a reclamação, totalmente, dos recursos em vigor, dadas as suas características, por certo, se se fizesse vista larga da sua origem legislativa.

Mas, pouco apresenta de comum com eles, numa compreensão mais exata, porque, se todos estão engastados num campo definido e certo, a reclamatória tem um raio de ação acessório, inespecificado, ou com melhor propriedade, restrita à disciplina, à correição do foro.

A maioria absoluta dos comentadores do Código de 73, como não poderia deixar de acontecer, anotam os mesmos recursos.

Alguns falam em reclamação, mas em maior número, para combatê-la. 
A reclamação, nem por isso ficou desamparada plenamente, sendo possível vislumbrá-la em estudos doutrinários, acórdãos, e nos Regimentos Internos de Tribunais.

Não há dúvida, entretanto, que a transigência é bem significativa.

\subsection{Nas Leis de Organização Judiciária}

Não há legislação federal sobre processo civil no Brasil, tal como está evidenciado, um recurso de reclamação.

Buscam-se, portanto, as suas características, a fim de ser entendido o espírito da jurisprudência que a vem adotando, nas legislações regionais, com a denominação de Leis de Organização Judiciária, bem assim nas disposições que constam nos Regimentos Internos elaborados pelos Tribunais.

O sentido criador da lei orgânica da justiça ultrapassa a sua órbita natural se pretender alcançar diretamente o processo, e menos atuação ainda pode ter o Regimento Interno, desde que, segundo Castro Nunes (1943, p. 117-118) neste se estabelecem as normas a seguir ao influxo dos trabalhos do Tribunal e demais disposições atinentes aos serviços da sua economia interna, apesar de ser costume consolidar no seu texto as normas constitucionais e legais respeitantes à organização do Tribunal e ao processo na parte aplicável à instância superior.

De modo geral, esses estatutos cuidam das reclamações se bem que, em alguns, sob feição administrativa.

Há os que avançam mais, todavia, dando-lhe destaque permissivo de interpretações elásticas e os que consideram o assunto em reserva.

Redigido em termos mais restritos que os presentes nos Regimentos Internos dos Tribunais de outros estados, o Regimento por que se regula o Tribunal de Justiça do Ceará, dedicando um capítulo à reclamação, fixa no art. 238 o seu conceito:

Contra despacho irrecorrível, poderão as partes, desde que haja necessidade de chamar o processo à ordem, para correção de erros, ou emendas de abusos, que importem em inversão tumultuária dos atos e fórmulas de ordenamento processual, reclamar dos atos judiciais praticados por Juiz de $1^{\circ}$. grau, dentro do prazo de cinco dias de sua ciência.

A redação do dispositivo não se limita a uma atitude de simples correção, como poderia ser entendido.

Na conceituação legal o legislador permitiu a interpretação ampla. Depois de dizer que cabe reclamação "para correção de erros", inseriu a palavra ou, tradutora de uma condição alternativa, para concluir o pensamento "emendas de abusos, que importem em inversão tumultuária dos atos e fórmulas de ordenamento processual”. 
O Regimento Interno do Tribunal de Justiça do Estado do Pará cogita reclamar de atos dos juízes, fixando seu conceito no art. 210. Mais notória está ali a sua aproximação dos recursos em a definindo quando, para o caso, não houver recurso específico.

A competência do Conselho Superior da Magistratura é prevista no art. 217, na seguinte hipótese: se o caso comportar penalidade disciplinar, a turma julgadora determinará a remessa dos autos ao Conselho Superior da Magistratura, para as providências pertinentes.

O Regimento Interno citado estabelece o modo de interposição e processamento das reclamatórias do art. 210 ao art. 217.

\subsection{A reclamação perante a Constituição Federal}

Longe o desejo de se proclamar a reclamação como um recurso e ainda mais distante o intuito de querer divisar essa autêntica exorbitância de poder como expressão de reconhecimento definido.

Nessa etapa de construção, num terreno de instabilidade, quando os exageros podem conduzir a adoção de um sentido contrário ao espírito do CPC e da própria Constituição, quer-se firmar posição oposta à hipertrofia de que se tratou até agora, significando a anomalia da reclamação, frente à Carta Magna, ao ser transformada em recurso.

Para isso, tem-se de invocar, como argumento decisivo, a letra mesma da Constituição.

$\mathrm{O}$ seu art. 22 dispõe: Compete privativamente à União legislar sobre: I direito civil, comercial, penal, processual, eleitoral, agrário, marítimo, aeronáutico, espacial e do trabalho.

Ora, é defeso ao Estado legislar em referência a processo, porque, no art. 25 , parágrafo $1^{\circ}$ a Constituição reserva aos Estados tão somente as competências que não lhes sejam, implícita ou explicitamente, vedadas.

Desde que a Carta Constitucional inadmite sequer a legislação estadual supletiva ou complementar, está eliminada qualquer dúvida a respeito. Aos Estados não resta base constitucional para feitura de leis que impliquem na invasão do campo reservado à União.

Estamos diante de uma situação incontroversa porque é a Constituição Federal que dá e ao mesmo tempo restringe a competência dos Estados.

A reunião de princípios disciplinares nas regras estabelecidas pelos poderes estaduais como matéria de direito orgânico da Justiça, não enseja uma inquinação qualquer de impropriedade legislativa, de falta de obediência ao preceito constitucional mas, a compreensão ampliada com a adoção de um recurso estranho ao CPC, conduz, inegavelmente, a um resultado que contraria a determinação da Lei Fundamental. 
De fato, se como medida disciplinar a reclamatória nada objetiva de anormal quando figura em Regimentos Internos dos Tribunais, anormalmente teria sua inclusão como recurso fora da codificação processual brasileira.

\section{ConsideraÇões Finais}

A reclamação, entendida como remédio judiciário sui generis, excepcional, mostra aspectos interessantes.

No conteúdo de sua acepção jurídica exprimindo correição, ou no sentido hipertrofiado de recurso, reveste feições diferenciadas.

E se a jurisprudência tem levado a caminhos que põem em evidência esse conflito, provocado pelos litigantes, entre a sistematização do CPC, feito sob amparo da permissão constitucional, e uma tendência criadora, apoiada em frágil arrimo, em normas descentralizadas e hierarquicamente inferiores, também aí, a mesma duplicidade de entendimento se oferece para dar autoridade legal incontroversa às correições parciais, quando funcionam como remédio disciplinar e não, quando exorbitam do verdadeiro sentido, arvoradas em recurso.

Possível é justificar a substância da correição parcial, da reclamação com finalidade disciplinar, em face de sua utilidade, do serviço assinalado que presta no intento de manter a ordem indispensável à boa administração da justiça e aos regulares trâmites do processo.

E se a reclamação-recurso pode desempenhar papel importante na defesa do direito da parte como suplemento de uma catalogação, e se mesmo é possível admitir um recurso inespecífico quando, como no nosso sistema de recursos, o legislador fez enumeração taxativa, não se encontra a reclamatória fixada em nosso direito positivo com o alicerce de que carece para ser aplicada, tal como se fora uma legítima forma de recorrer.

Nem mesmo o precedente histórico abrandaria essa positiva irregularidade.

É intuitivo que a reclamação disciplinar, correcional, nesse quadro do direito brasileiro atual tem lugar assegurado no sistema que separa as competências para legislar entre a União e os Estados, enquanto a outra reclamatória (reclamação-recurso) magoa as regras essenciais, foge do tipo normal mostrando nítido aspecto de anomalia.

Partindo do ponto central, da Constituição, torna-se imperativa a conclusão de que marginalmente ao Estatuto Básico não pode prosperar um corpo de regras contrárias aos fundamentos ou à formalização que impõe.

E nesse caso, o CPC é o único veículo legítimo, pela sua redação inicial ou pelas normas federais que a ele se vierem incorporar sem caráter derrogatório, para a criação de recursos e dar a medida de seu comportamento no direito positivo brasileiro. 
A própria regra elaborada pelo povo brasileiro, por seus representantes em Assembléia Constituinte, sabedora de que ficou aos Estados apenas o direito de organizar sua justiça e, mais particularmente aos Tribunais, a faculdade de ditarem suas regras regimentais, dispôs:

Art. 125. Os Estados organizarão sua Justiça, observados os princípios estabelecidos nesta Constituição.

$\S 1^{\circ}$ - A competência dos tribunais será definida na Constituição do Estado, sendo a lei de organização judiciária de iniciativa do Tribunal de Justiça.

Bastaria o citado preceito ao destaque da feição anômala que escolhemos quanto à reclamação e quanto à reclamação-recurso. Ele, por si, teria força para arrastar com a letra pura da lei essa tentativa hipertrófica a um desalentador e irremediável resultado negativo. Contudo, o espírito, o sentido lógico dado ao artigo, em combinação com os intuitos que presidiram a elaboração de nosso CPC, corroboram fortemente à conclusão enunciada.

Na verdade, os antigos argumentos em favor de direito processual único para todo o território nacional revivem, agora, a fim de que não se admita, de novo, um modo diferente de aplicar o direito nas várias porções territoriais do organismo político do Estado Brasileiro, conforme o número variado de Regimentos Internos, único em cada Estado.

Não seriam as legislações esparsas, regionais, capazes de alterar a lei de atuação nacional.

A Constituição é clara ao reservar ao Legislativo Federal o direito de estabelecer leis processuais.

E a legislação orgânica dos Estados, bem assim os Regimentos Internos de Tribunais, incorporados às máximas por que se regem ao Judiciário, tem significação reduzida sem que possam imprimir reflexo maior nas linhas mestras do processo normalmente criado.

Entender por outro modo é desvirtuar o sentido da hierarquia das leis que fincamos em manter inviolável.

Que os Estados estabeleçam, como ocorre, a reclamação para fins disciplinares estará correto; mas que a estendam aos domínios da lei processual criando recurso novo, não previsto no $\mathrm{CPC}$, é dar rumo duvidoso, injustificável e sem valia.

Não será ilícito, senão por outra lei federal, na estruturação de nosso sistema legislativo, no regime de prévia ordenação legal em que vivemos aceitar novos meios de recorrer. Por isso mesmo, sendo a reclamação, como recurso, um remédio que se não coaduna com a lei vigente, quer na sua manifestação constitucional, seja no seu revestimento e conteúdo ordinário, embora tendo encontrado apoio na jurisprudência e utilização forense pela atuação das partes, é, no sentido legal, medida essencialmente anômala. 


\section{REFERÊNCIAS}

Livros:

ALMEIDA, Cândido Mendes de. Ordenações Filipinas. Rio de Janeiro: Fundação Calouste Gulbenkian, 1870.

ARAGÃO, Egas Moniz de. A correição parcial. Curitiba: Imprensa da Universidade Federal do Paraná, 1969.

DINAMARCO, Candido Rangel. Nova era do processo civil. São Paulo: Malheiros, 2004.

FERREIRA, Aurélio Buarque de Holanda. Novo Dicionário Aurélio da Língua Portuguesa. 3. ed. Curitiba: Positivo, 2007.

NERY JÚNIOR, Nelson; WAMBIER, Teresa Arruda Alvim (coords.). Anotações sobre a teoria geral dos recursos. São Paulo: Revista dos Tribunais, 1999.

NUNES, Castro. Teoria e Prática do Poder Judiciário. Rio de Janeiro: Forense, 1943. PORTANOVA, Rui. Princípios do Processo Civil. 6. ed. Porto Alegre: Livraria do Advogado, 2005.

TORRES, Guillermo Cabanellas De. Diccionario Juridico Elemental. 4. ed. Buenos Aires: Heliasta S.R.L., 2006.

\section{Documentos Jurídicos:}

BRASIL. Constituição (1988). Constituição da República Federativa do Brasil, Brasília, DF, Senado, 1988.

. Lei n. ${ }^{0}$ 5.869/73, de 11 de Janeiro de 1973. Código de Processo Civil, Disponível em: <http://www.planalto.gov.br/ccivil_03/Leis/L5869.htm>. Acesso em: 03 fev. 2009.

. Decreto-Lei n. ${ }^{0}$ 5.452/43, de 01 de Maio de 1943. Consolidação das Leis do Trabalho, Disponível em: $<$ http://www.planalto.gov.br/ccivil_03/Decreto-Lei/ Del5452.htm>. Acesso em: 03 fev. 2009.

CEARÁ. Regimento Interno do Tribunal de Justiça do Estado do Ceará, Disponível em: $<$ http://www.tjce.jus.br/institucional/pdf/regimento_interno_tjce. pdf>. Acesso em: 03 fev. 2009.

PARÁ. Regimento Interno do Tribunal de Justiça do Estado do Pará, Disponível em: $<$ http://www.tj.pa.gov.br/legislacao/pdf/RegimentoInterno2008. pdf>. Acesso em: 03 fev. 2009. 
Periódicos:

DINAMARCO, Candido Rangel. A Reclamação no processo civil brasileiro. Revista Forense, Rio de Janeiro, v. 99, n. 366, p. 9-16, mar./abr. 2003.

GRINOVER, Ada Pellegrini. Da reclamação. Revista Brasileira de Ciências Criminais, São Paulo, v. 10, n. 38, p. 75-83, abr./jun. 2002.

MOREATO, Leonardo L. A Reclamação constitucional e a sua importância para o Estado democrático de direito. Revista de Direito Constitucional e Internacional, São Paulo, v. 13, n. 51, p. 171-187, abr.jun. 2005.

PACHECO, José da Silva. A "reclamação" no STF e no STJ de acordo com a nova Constituição. Revista dos Tribunais, São Paulo, v. 78, n. 646, ago. 1989.

\section{ANOMALOUS ASPECTS OF THE CLAIM BEFORE BRAZIL'S CIVIL PROCEDURAL LAW}

Abstract: The claim is an institute that tends to function as non specific and supplementary remedy. Despite the existence of prompt divergences, the claim concept is pacific in terms of relevance for the effectiveness of the process. It has legal prevision in the internal regulations of the Brazilian Courts. The claim assumes visible characteristics of anomaly, before Brazil's civilian procedural systematics. It is a judiciary remedy of correctional character that aims to reppeal acts or ommissions by judges of first degree of jurisdiction, when, by their very nature, such acts or ommissions would be unappealable.

Keywords: Claim. Internal Regulations. Appeal. 